\title{
Parametric characterizations in superparamagnetic latex
}

\author{
SEDA BEYAZ ${ }^{\mathrm{a}, *}$, HAKAN KOCKAR ${ }^{\mathrm{b}}$ and TANER TANRISEVER ${ }^{\mathrm{a}}$ \\ ${ }^{a}$ Chemistry Department, ${ }^{b}$ Physics Department, Science and Literature Faculty, Balikesir University, \\ 10145 Balikesir, Turkey
}

MS received 16 October 2012; revised 19 December 2012

\begin{abstract}
The effect of synthesis parameters on the production of superparamagnetic latex, which are magnetite nanoparticles covered with a poly(methyl methacrylate) layer, were studied. The synthesis method was based on the developed route of emulsifier-free emulsion polymerization. Under this study, effects of the monomer and initiator concentrations, the amount of magnetic sol, the stirring rate and the adding rate of the magnetic sol on the properties of synthesized latexes were investigated. The characterizations were performed by a high resolution transmission electron microscopy, a dynamic light scattering, a vibrating sample magnetometer and a gel permeation chromatography. The results showed that the monomer concentration was found to be the most effective parameter on latex stability. As the initiator amount and the stirring rate increased, saturation magnetization and average molecular weight decreased due to the reactions occurring between surfaces of magnetite nanoparticles and initiator fragments. On increasing amount of magnetic sol, the saturation magnetization and polymer molecular weight increased but the size of nanospheres was unchanged because of the ions in magnetic sol. It was seen that the desired size and magnetic properties of the latex could be obtained since the parameters were found to have substantial impact on their properties.
\end{abstract}

Keywords. Superparamagnetic latex; magnetite nanoparticles; emulsifier-free; emulsion polymerization.

\section{Introduction}

Superparamagnetic latexes (or smart polymeric nanobeads) are colloidal dispersions of polymeric nanospheres including small single-domain magnetic nanoparticles such as iron oxide. Their magnetization is, compared to normal paramagnetic materials, much higher and can reach nearly the saturation magnetization of ferromagnetic iron oxide. This behaviour allows the tracking of such particles in a magnetic field gradient without loosing the advantage of a stable colloidal suspension. Owing to this magnetic property, they have been widely used in diverse fields such as tissue repair (Philippova et al 2011), drug delivery systems (Neuberger et al 2005), hyperthermia (Babincová et al 2000), magnetic resonance imaging (Dutz et al 2009), bioseparation (Filipcsei et al 2007), enzyme immobilization (Mornet et al 2006) and oil industry (Philippova et al 2011).

Incorporation of magnetic nanoparticles into polymeric nanospheres has been achieved by various polymerization methods such as suspension (Hasell et al 2007), inverse emulsion (Wormuth 2001), microemulsion (Liu et al 2003), mini-emulsion (Zheng et al 2005) and dispersion polymerization (Horak et al 2004). In these studies, conventional polymerization stabilizers were often preferred

\footnotetext{
*Author for correspondence (sedacan@balikesir.edu.tr)
}

to obtain stable colloids. However, they could negate the properties of nanoparticles such as the magnetic separation capability. In this respect, emulsifier-free emulsion polymerization can be thought of as a much suitable way for preparing magnetic latex. Because ionizable initiators, hydrophilic co-monomers or ionic co-monomers stabilize polymer particles in such polymerization systems and thus, there is no need to add any surfactant. However, in order to enhance the interaction between magnetic nanoparticles and polymers, some researchers (such as Pich et al 2005a, b) working on this method also had to use emulsifiers such as dodecanoic acid (Wang et al 2004), sodium dodecylsulfonate (Xie et al 2003) and consequently, more uniform distribution of magnetic nanoparticles inside polymer spheres were obtained. For the same purpose, Utkan et al (2011) tried polymers (short chains) such as poly(ethylene glycol) methacrylate and poly(ethylene glycol) ethyl ether methacrylate in the presence of styrene and a cationic comonomer. Besides, Lee et al (2008) carried out synthesis of nanoparticles in a cross-linked latex prepared by emulsifier-free emulsion polymerization, but it is hard to get enough reported information about magnetic nanoparticles and the magnetic properties of composite latexes. In recent years, emulsifier-free mini-emulsion polymerization, which is different from the emulsifier-free emulsion polymerization, was used for the encapsulation of magnetite nanoparticles into polystyrene particles by Faridi-Majidi 
and Sharifi-Sanjani (2006, 2007). Furthermore, FaridiMajidi's polymerization recipes also included various components such as monomer, co-stabilizer, ionic initiator and magnetite nanoparticles coated with oleic acid.

To our knowledge, there have been investigations for the synthesis of superparamagnetic latexes by using surfactants and thus, a new route based on homogeneous nucleation mechanism (Fitch 1973) of methyl methacrylate (MMA) was introduced without using surfactants (Beyaz et al 2011). There are only four main components: methyl methacrylate, potassium persulfate, water and magnetite nanoparticles as compared with the other work. The latexes were synthesized and a very limited effect of monomer concentration alone on them was performed (Beyaz et al 2011). Therefore, a compressive work on the new parameters of the monomer and also initiator concentration, the amount of magnetic sol, the stirring rate and the adding rate of the magnetic sol for the synthesized latex is required. The results of the current parameters impact are discussed and presented here. It is seen that a new insight in obtaining superparamagnetic latex has been developed with desired size and magnetic properties, which are important for technological applications in the industry.

\section{Experimental}

\subsection{Materials}

MMA from Merck was freed from phenolic inhibitors by shaking with $5 \%$ aqueous sodium hydroxide, washing with water and drying over sodium sulphate. The initiator, potassium persulphate (KPS), was a product of Fluka. Ferric chloride hexahydrate $\left(\mathrm{FeCl}_{3} \cdot 6 \mathrm{H}_{2} \mathrm{O}\right.$, purity, $\left.>99 \%\right)$, aqueous ammonia $\left(25 \% \mathrm{NH}_{3}\right.$ in water, w/w) and perchloric acid $\left(\mathrm{HClO}_{4}, 60 \%\right.$, w/v) were obtained from Merck. Ferrous chloride tetrahydrate $\left(\mathrm{FeCl}_{2} \cdot 4 \mathrm{H}_{2} \mathrm{O}\right.$, purity, $\left.99 \%\right)$ was purchased from Fluka. Double-distilled water was used in all stages of the workup. The conductivity of water was measured at about $1.0-1.5 \mu \mathrm{s} / \mathrm{cm}$ at $25^{\circ} \mathrm{C}$.

\subsection{Magnetic nanoparticles and magnetic sol}

Magnetic nanoparticles were synthesized according to the Massart (1981) method (Beyaz et al 2009; Karaagac et al 2010). For an acidic magnetic sol, the magnetic precipitate was stirred with aqueous $2 \mathrm{M} \mathrm{HClO}_{4}$ and was then isolated by centrifugation. After the process was repeated twice, its peptization was accomplished merely by adding water.

The magnetic nanoparticles sized about $9 \mathrm{~nm}$ consist of magnetite structure. They are superparamagnetic and their saturation magnetization is $50 \mathrm{emu} / \mathrm{g}$. The concentration of magnetite in diluted magnetic fluid was $3.51 \times$ $10^{-2} \mathrm{~g} / \mathrm{mL}$ (Beyaz et al 2011).

\subsection{Synthesis of magnetic latexes}

Polymerization system was set up as described in Beyaz et al (2011), the appropriate amounts of water and MMA were charged into the reactor and stirred under nitrogen atmosphere for about $60 \mathrm{~min}$ to remove oxygen from the reaction system. Temperature equilibrium was attained and the aqueous phase was saturated with monomer. The initiator, KPS, dissolved in $50 \mathrm{~mL}$ water, was added into the reactor. After the start of polymerization, magnetic sol was dropped into polymerization system at 2.5-5 min of polymerization. Polymerizations were carried out using a total of $950 \mathrm{~mL}$ water for about $90 \mathrm{~min}$. The synthesis conditions are listed in table 1.

\subsection{Characterization techniques}

Dynamic light scattering (DLS) studies were conducted using Zetasizer NanoZS (Malvern Instruments) for hydrodynamic radius $\left(R_{\mathrm{H}}\right)$ and the polydispersity index $\left(\mathrm{PDI}=\mu_{2} / \Gamma^{2}\right)$ of magnetic latex. Before measurements, the latexes were highly diluted till they became transparent. Thereafter, the samples were introduced into a thermostated scattering cell at $25^{\circ} \mathrm{C}$.

A high resolution transmission electron microscope (HRTEM, FEI TECNAI G ${ }^{2}$ F30 model) with an accelerating voltage of $300 \mathrm{kV}$ and a scanning transmission electron microscope (STEM, FEI QUANTA 200F model) was used to obtain information about the morphology of magnetic polymer particles and the efficiency of magnetite encapsulation. Samples for HRTEM and STEM were prepared by placing a drop of very dilute magnetic polymer dispersion on a copper grid covered by Formvar foil and drying. A vibrating-sample magnetometer (VSMADE EV9 Model) was employed under $\pm 20 \mathrm{kOe}$ of magnetic field with 1 Oe step at room temperature to investigate the magnetic properties of magnetic latex.

Aqueous $2 \mathrm{M} \mathrm{HCl}$ solution in volumetric flask for $48 \mathrm{~h}$ was added to the magnetic latexes at room temperature to determine amount of free $\mathrm{Fe}_{3} \mathrm{O}_{4}$ particles without coating the polymer. After the suspension was centrifuged, the upper fraction was restrained for chemical analysis with thiocyanate (Zaitsev et al 1999).

The magnetic nanoparticles should be separated from polymeric composite to determine molecular weight of polymers. For this to happen, dried composite samples were dissolved in chloroform and a pinch of iron powder was added to the solution. The magnetic nanoparticles in the solution adsorbed on the surface of the iron powder due to the effect of magnetic field produced by a magnet which is under the vessel of the solution at about $5 \mathrm{~h}$. It was observed that the polymers suspended, while the magnetite nanoparticles precipitated in chloroform. Hence, polymer solution was extracted and used to determine the average molecular weight $\left(M_{\mathrm{n}}\right)$ and 
Table 1. Properties and synthesis conditions of superparamagnetic lattices.

\begin{tabular}{|c|c|c|c|c|c|c|c|c|}
\hline \multicolumn{2}{|c|}{ Series* } & \multirow[t]{2}{*}{ Variable } & \multirow[t]{2}{*}{$R_{\mathrm{T}}(\mathrm{nm})^{\mathrm{b}}$} & \multirow[t]{2}{*}{$R_{\mathrm{H}}(\mathrm{nm})$} & \multirow[t]{2}{*}{ PDI } & \multirow[t]{2}{*}{$M_{\mathrm{n}}(\mathrm{kg} / \mathrm{mol})$} & \multirow[t]{2}{*}{$M_{\mathrm{w}} / M_{\mathrm{n}}$} & \multirow[t]{2}{*}{$M_{\mathrm{s}}(\mathrm{emu} / \mathrm{g})$} \\
\hline I $\quad[\mathrm{N}$ & MMA] (M) & & & & & & & \\
\hline & ML1 & $0 \cdot 15$ & $155 \pm 10$ & 226 & 0.098 & $68 \cdot 34$ & $2 \cdot 91$ & $0 \cdot 231$ \\
\hline & ML2 & $0 \cdot 20$ & $196 \pm 27$ & 236 & $0 \cdot 002$ & $85 \cdot 63$ & $2 \cdot 67$ & $0 \cdot 297$ \\
\hline & ML3 & $0 \cdot 30$ & - & 275 & $0 \cdot 022$ & $80 \cdot 54$ & $2 \cdot 89$ & $0 \cdot 184$ \\
\hline & ML4 & $0 \cdot 40$ & $247 \pm 44$ & 296 & $0 \cdot 048$ & - & - & $0 \cdot 171$ \\
\hline \multicolumn{9}{|c|}{ II $\quad[\mathrm{KPS}]\left(\times 10^{3} / \mathrm{M}\right)$} \\
\hline & ML6 & 1 & $162 \pm 20$ & 206 & $0 \cdot 010$ & $89 \cdot 01$ & 2.78 & $0 \cdot 395$ \\
\hline & ML2 & 2 & $196 \pm 27$ & 236 & $0 \cdot 002$ & $85 \cdot 63$ & $2 \cdot 67$ & $0 \cdot 297$ \\
\hline & ML5 & 3 & - & 254 & $0 \cdot 003$ & $76 \cdot 65$ & $2 \cdot 72$ & $0 \cdot 277$ \\
\hline \multirow[t]{5}{*}{ III } & Magnetic sol (mL) & & & & & & & \\
\hline & L1 & 0 & - & 223 & 0.009 & $113 \cdot 42$ & $2 \cdot 84$ & - \\
\hline & ML2 & 10 & $196 \pm 27$ & 236 & 0.002 & $85 \cdot 63$ & $2 \cdot 67$ & $0 \cdot 297$ \\
\hline & ML7 & 20 & $192 \pm 16$ & 225 & $0 \cdot 050$ & 86.98 & $2 \cdot 29$ & $0 \cdot 568$ \\
\hline & ML8 & 40 & - & 227 & $0 \cdot 037$ & $106 \cdot 72$ & $2 \cdot 27$ & $1 \cdot 210$ \\
\hline \multirow[t]{5}{*}{ IV } & Stirring rate $(\mathrm{rpm})$ & & & & & & & \\
\hline & ML9 & 100 & - & 219 & $0 \cdot 002$ & $102 \cdot 48$ & $2 \cdot 27$ & $0 \cdot 298$ \\
\hline & ML2 & 300 & $196 \pm 27$ & 236 & 0.002 & $85 \cdot 63$ & $2 \cdot 67$ & $0 \cdot 297$ \\
\hline & ML10 & 400 & - & 218 & 0.023 & $79 \cdot 50$ & $2 \cdot 78$ & $0 \cdot 266$ \\
\hline & ML11 & 500 & $167 \pm 22$ & 203 & $0 \cdot 008$ & $69 \cdot 00$ & $2 \cdot 81$ & $0 \cdot 260$ \\
\hline \multirow[t]{5}{*}{$\mathrm{V}$} & Adding rate $(\mathrm{mL} / \mathrm{min})^{\mathrm{a}}$ & & & & & & & \\
\hline & ML11 & 4 & $167 \pm 22$ & 203 & $0 \cdot 008$ & $60 \cdot 00$ & $2 \cdot 81$ & $0 \cdot 260$ \\
\hline & ML12 & 7 & - & 192 & 0.002 & $60 \cdot 90$ & $3 \cdot 14$ & $0 \cdot 270$ \\
\hline & ML13 & 10 & - & 205 & $0 \cdot 018$ & 62.60 & $3 \cdot 06$ & $0 \cdot 281$ \\
\hline & ML14 & 20 & $120 \pm 07$ & 155 & 0.002 & $91 \cdot 56$ & $2 \cdot 38$ & $0 \cdot 324$ \\
\hline \multirow[t]{3}{*}{$\mathrm{Va}$} & ML10 & 4 & - & 218 & 0.023 & $79 \cdot 50$ & $2 \cdot 78$ & $0 \cdot 266$ \\
\hline & ML15 & 17 & - & 199 & 0.009 & - & - & 0.323 \\
\hline & ML16 & 60 & - & 191 & 0.003 & - & - & $0 \cdot 343$ \\
\hline
\end{tabular}

*Series; I: $[\mathrm{KPS}]=2 \times 10^{-3} \mathrm{M}$, magnetic sol $=10 \mathrm{~mL}$, stirring rate $=300 \mathrm{rpm}$, adding rate $=4 \mathrm{~mL} / \mathrm{min}$. II: $[\mathrm{MMA}]=0 \cdot 2 \mathrm{M}$, magnetic sol $=10 \mathrm{~mL}$, stirring rate $=300 \mathrm{rpm}$, adding rate $=4 \mathrm{~mL} / \mathrm{min}$ III: $[\mathrm{KPS}]=2 \times 10^{-3} \mathrm{M}, \quad[\mathrm{MMA}]=0 \cdot 2 \mathrm{M}, \quad$ stirring rate $=300 \mathrm{rpm}$, adding rate $=$ variable. IV: $[\mathrm{KPS}]=2 \times 10^{-3} \mathrm{M},[\mathrm{MMA}]=0 \cdot 2 \mathrm{M}$, magnetic sol $=10 \mathrm{~mL}$, adding rate $=4 \mathrm{ml} / \mathrm{min}, \mathrm{V}:$ $[\mathrm{KPS}]=2 \times 10^{-3} \mathrm{M},[\mathrm{MMA}]=0.2 \mathrm{M}$, stirring rate $=500 \mathrm{rpm}$, magnetic sol $=10 \mathrm{~mL}$. Va: $[\mathrm{KPS}]=2 \times 10^{-3} \mathrm{M},[\mathrm{MMA}]=0 \cdot 2 \mathrm{M}$, stirring rate $=400 \mathrm{rpm}$, magnetic sol $=10 \mathrm{~mL}$. ${ }^{\text {a }}$ The speed at which magnetic sol was added. ${ }^{\mathrm{b}}$ Average particle diameters obtained from electron micrographs.

polydispersity index $\left(M_{\mathrm{w}} / M_{\mathrm{n}}\right)$ using gel permeation chromatography (GPC). GPC consisted of an Agilent Iso Pump, a refractive index detector, both Mixed ' $D$ ' and Mixed 'E' columns (e.g. Polymer Labs), and calibration was carried out using PMMA calibration standards. The GPC eluent was HPLC grade tetrahydrofuran (THF) stabilized with BHT, at a flow rate of $1.0 \mathrm{~mL} / \mathrm{min}$.

\section{Results and discussion}

Table 1 presents various series of magnetic latexes synthesized at various experimental conditions. It also summarizes properties of the latexes such as particle size, polymer molecular weight and saturation magnetization. In the following sections, new polymerization parameters of the route were evaluated in terms of latex properties.

\subsection{Monomer concentration}

On increasing the concentration of MMA, the hydrodynamic radius and the sizes of magnetic latexes obtained from dynamic light scattering (DLS) and electron microscopy images, respectively increased as listed in table 1 . This result is attributed to the decrease at the mole ratio of the radical to monomer as described by Tanrisever et al (1996). At high monomer concentrations, it is noticed that there have been big brown particles (called aggregate) in the polymerization system (see figures 1(a) and $2(\mathrm{a})$ ). In order to explain the observation, the aggregates have been removed from latex by filtration, dried and then recorded by weighing. As expected, it was found that the amounts of aggregate are $0.045 \mathrm{~g}$ and $0.383 \mathrm{~g}$ for 0.3 and $0.4 \mathrm{M}$ monomer, respectively. The reason of aggregation is that the increase in monomer concentration in presence of magnetite nanoparticles leads to a further decrease of surface charge per primer particle at stage 1 and much more increase of coagulation occurred at stage 2. Thus, the uncontrollable rapid coagulation produced very big unstable particles called aggregates.

PDI results presented in table 1 indicated that particle size distributions of latex particles with highest and lowest monomer concentrations were highly expanded when 
compared with $0.2 \mathrm{M}$ monomer. As seen in figure 1(a), it can be said that the reason for the broad particle size distribution of polymerization system with $0.4 \mathrm{M}$ monomer is aggregation. But, this statement is invalid for $0.15 \mathrm{M}$ monomer as seen in STEM image of figure 1(b) due to the free magnetite nanoparticles. They are adsorbed onto polymeric particle surface and reduced surface charge of latex particle as clearly seen at HRTEM image of figure 2(a). In accordance with this observation, percentage of the free magnetite nanoparticles was calculated as $40 \%$ by chemical analysis with thiocyanate (Zaitsev et al 1999). It was disclosed that the time interval of stage 1 suddenly diminishes with decreasing monomer concentration at the emulsifier-free emulsion polymerization kinetic of MMA (Tanrisever et al 1996). As a result of this, the coagulation of primer particles had been partly finished at which the magnetic sol was added to polymerization system. Thus, a major part of magnetite nanoparticles was left out of the polymeric nanospheres.

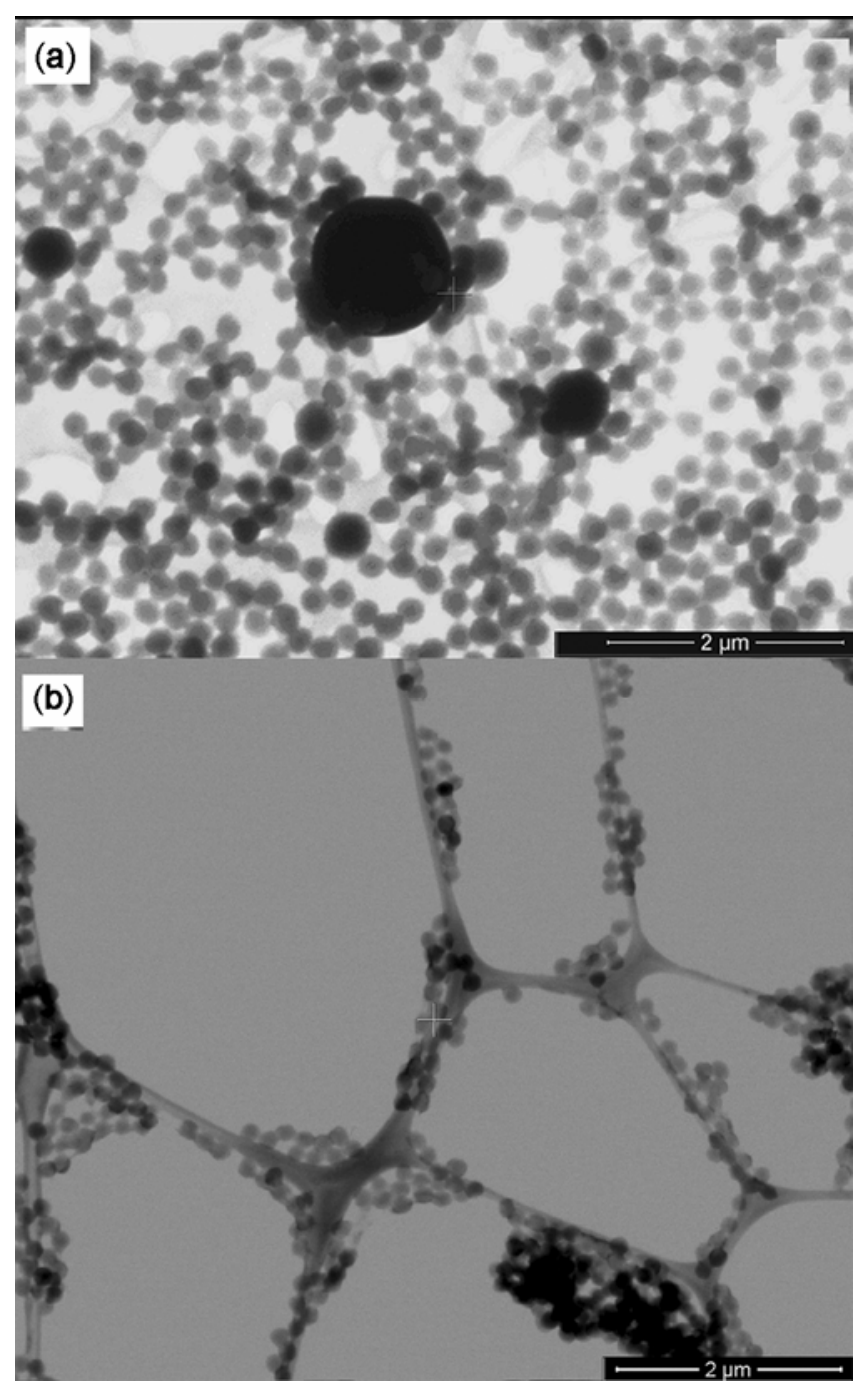

Figure 1. STEM photographs of magnetic latex with monomer concentrations: (a) 0.4 and (b) $0.15 \mathrm{M}$.
It should also be noted that the most effective magnetic loading into polymer nanospheres in the series was obtained for $0.2 \mathrm{M}$ monomer concentration as in figure 2(b).

Saturation magnetization, $M_{\mathrm{s}}$, values obtained from magnetization curve measured by vibrating sample magnetometer (VSM) vs the monomer concentrations were shown in table 1 . It was expected that $M_{\mathrm{s}}$ decreased with increasing monomer concentration since the magnetite to monomer amount ratio decreased as reported earlier (Xie et al 2003; Pitch et al 2005a). However, $M_{\mathrm{s}}$ value of magnetic latex particles with $0.15 \mathrm{M}$ monomer was measured lower than the one with $0.2 \mathrm{M}$ monomer in the study. The reason for that might be the free magnetite particles in this sample may have provided the following reactions (Kolthoff et al 1951):

$$
\begin{aligned}
& \mathrm{Fe}^{+2}+\mathrm{S}_{2} \mathrm{O}_{8}^{-2} \rightarrow \mathrm{SO}_{4}^{-\bullet}+\mathrm{SO}_{4}^{-2}+\mathrm{Fe}^{+3} \\
& \mathrm{Fe}^{+2}+\mathrm{SO}_{4}^{-\bullet} \rightarrow \mathrm{Fe}^{+3}+\mathrm{SO}_{4}^{-2}
\end{aligned}
$$

Since, especially the rate constant of second reaction is bigger (Kolthoff et al 1951), a decrease in the activity of initiator may be expected. Indeed, as an example, yield of the polymerization system with $0.15 \mathrm{M}$ monomer was found to be lower $(\sim 88 \%)$ than latex $(\sim 97 \%)$ without magnetite nanoparticles.

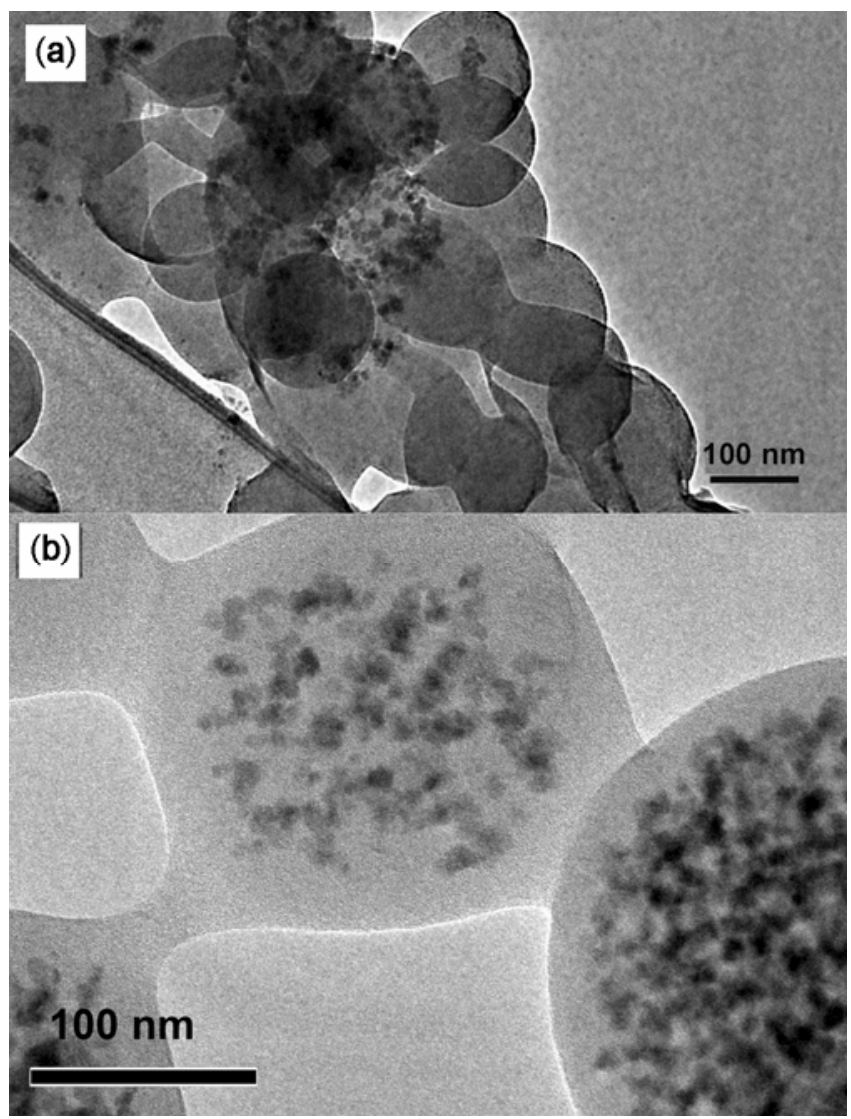

Figure 2. HRTEM photographs of magnetic latex with monomer concentrations of (a) $0 \cdot 15$ and (b) $0 \cdot 20 \mathrm{M}$. 
Polymer molecular weights for different MMA concentrations were collected in table 1 . The average molecular weight of polymers increased with rise in monomer concentration. Since this trend is also seen at the emulsifierfree emulsion polymerization of MMA as reported in Tanrisever et al (1996), it can be concluded that no impact of magnetic nanoparticles has been observed for monomer series.

The results indicated that the amount of MMA in this polymerization system has significant effect on particle size, size distribution and magnetic properties of latex. The most stable, monodisperse and fine magnetic latex was achieved at $0.20 \mathrm{M}$ MMA and was selected for further experiments.

\subsection{Initiator concentration}

As KPS concentration increased, average hydrodynamic radius of the magnetic latex increased as seen in table 1 . For initiator concentration, variation of the particle size may be attributed to the fact that increased initiator amount led to a higher number of primary particles; therefore, a smaller particle size for resulting latexes was obtained (Tanrisever et al 1996). On the other hand, increase in the initiator amount increased the electrolyte concentration in the polymerization system; this depressed the electrical double layer of the primary particle surface and bigger latexes were obtained, which is called 'salt effect' (Can and Tanrisever 2007). When one of these two factors was predominant over the other one, particles of the resulting latexes were slightly bigger or smaller. In this study, it was observed that the second factor may be predominant.

Neither aggregation nor free magnetite on the surface of the polymeric nanospheres was observed in this series. The particle size distribution of latexes with $1 \times 10^{-3} \mathrm{M}$ KPS seems to be broader than others (see table 1). At low KPS concentration, the magnetic sol was added to the more heterogeneous polymerization medium as a result of extension of time intervals at stage 1 and thus the broad size distribution was observed.

Table 1 also shows that $M_{\mathrm{s}}$ values of latexes decreased with increasing KPS in the order of $3 \times 10^{-3} \mathrm{M}<2 \times$ $10^{-3} \mathrm{M}<1 \times 10^{-3} \mathrm{M}$. It is clearly seen that $M_{\mathrm{s}}$ was high at low initiator concentration. As mentioned above, the reactions between $\mathrm{Fe}^{+2}$ on the surface of magnetite and $\mathrm{S}_{2} \mathrm{O}_{8}^{-2}$ can decrease the $M_{\mathrm{s}}$ values, since magnetite was turned to maghemite which had low $M_{\mathrm{s}}$ as a result of the oxidation from $\mathrm{Fe}^{+2}$ to $\mathrm{Fe}^{+3}$ (Sun et al 2004).

In table 1, polymers with lower molecular weight were formed when the initiator concentration was increased. This relation is also valid for classic emulsifier-free emulsion polymerization of MMA (Tanrisever et al 1996). It seems that there is no significant effect of the reaction between magnetite surface and initiator on the molecular weight of the synthesized polymers.

\subsection{Magnetic sol amount}

The different amounts of magnetic sol were investigated at the same time intervals during the polymerization process. It was found that the sizes of the magnetic latexes fluctuate around $230 \mathrm{~nm}$ with little change even if magnetic sol amounts were changed as shown in table 1 . Thus, no substantial effect of the magnetic sol amount on the particle size was observed. There were two possible opposite effects causing the result: one was that the higher the magnetic sol concentration, the greater the number of seed particles in the polymerization, thus, decreasing particles size as reported earlier (Xie et al 2003; Pich et al 2005a). However, the other possibility is that, with a higher magnetic sol concentration, the primer particle coagulation occurred more frequently because of the high electrolyte concentration accompanied with magnetite nanoparticles (Can and Tanrisever 2007). Thus, there was no significant difference for the particle sizes since it is thought that two effects mentioned above compensated each other.

Table 1 also shows that the increase of magnetic sol volume has expanded the particle size distribution. This effect may be due to the increase of coagulation as a result of the high electrolyte concentration. Because the findings obtained by the chemical analysis exhibited that there is no free magnetite nanoparticle that could cause coagulation like sample ML1 as seen in figure 2(a).

According to the results in table 1, first, the addition of magnetic sol caused a decrease in the polymer molecular weight and then an increase as the amount of magnetic sol was further increased. Additions of ferrous iron in excess can lead to the rapid decomposition of KPS because of reaction with bigger rate constant in (2) (Block et al 2004). Thus, the magnetic nanoparticles initially activated the KPS and caused the formation of low molecular weight. But then with an increasing amount, KPS decomposed and high molecular weight was observed.

Magnetization curves for dried latexes bearing different magnetite contents are presented in figure 3(b). Although the magnetic response to external field increased with increase in the amount of the magnetic sol, all lattices were still superparamagnetic. $M_{\mathrm{s}}$ values obtained from magnetization curves were proportional to the deposited magnetite content, that showed all magnetite nanoparticles were coated with polymeric layer, and consequently, their magnetizations were protected against the reactions. Due to the drawbacks of the coagulation and polydispersity, we have not launched more than $3.1 \%$, initial ratio of magnetite/monomer. However, the deposited magnetite content is enough to achieve considerable magnetic response to external magnetic field as seen in figure 3(a). $M_{\mathrm{s}}$ values were high as compared with some studies (such as $\mathrm{Gu}$ et al 2005; Pich et al 2005a), in which the same amounts of magnetic nanoparticles could 
be deposited. In addition, the magnetization of latexes could be enhanced by removing non-magnetic spheres from the latex. For this, a magnet was placed under the vessel of latex for about $5 \mathrm{~h}$. Thereafter, upper part of
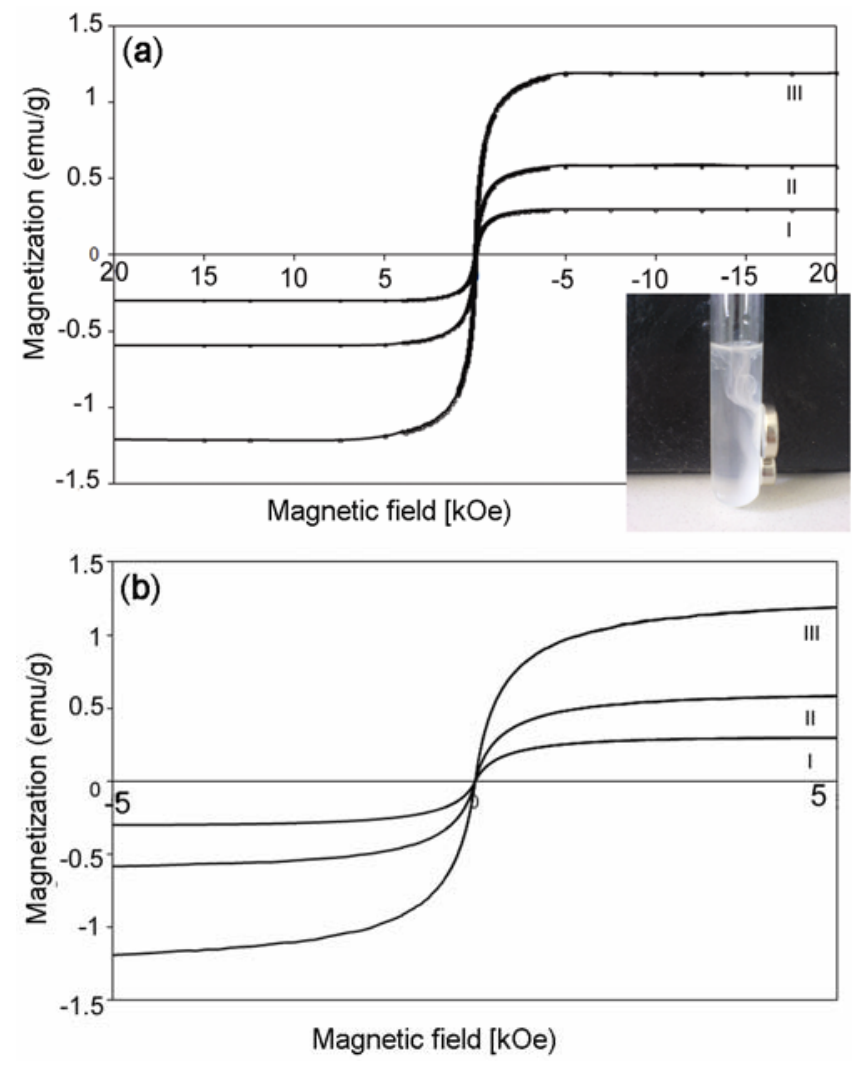

Figure 3. Magnetization curves of superparamagnetic polymeric particles with different magnetite contents: I: $0.786 \%$, II: $1 \cdot 534 \%$, III: $3 \cdot 111 \%$; (a) at $\pm 20 \mathrm{kOe}$ and (b) $\pm 5 \mathrm{kOe}$.
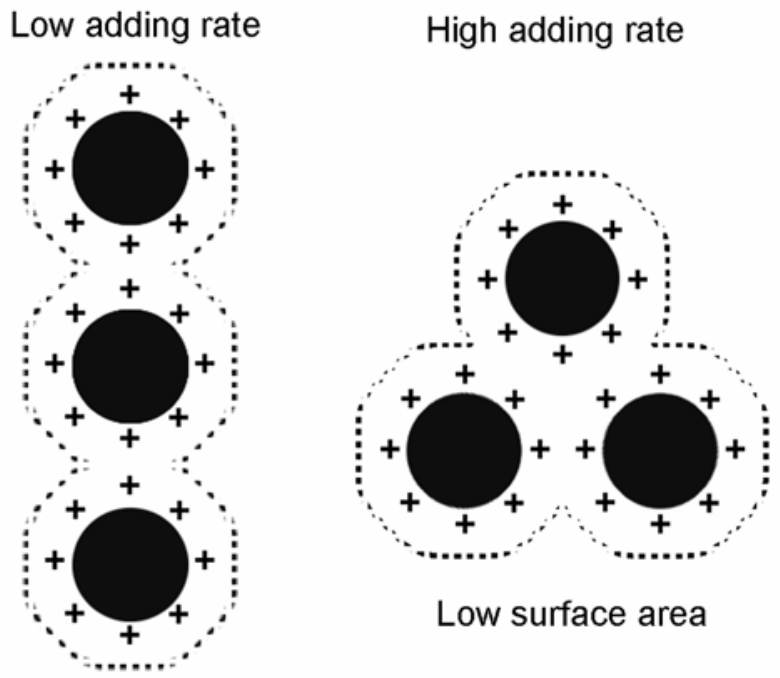

High surface area

Figure 4. Simulation of relation between adding rate and total surface area for magnetic nanoparticles. the latex was decanted slowly; the rest of it, magnetic part, was dried for VSM measurement. It was seen that the values of $M_{\mathrm{s}}$ increased by about 10 fold in most of the latexes.

\subsection{Stirring rate}

As shown in table 1, it was found that the particle size was small in low $(100 \mathrm{rpm})$ stirring rate since the monomer transport rate from monomer droplets to the aqueous phase, which controls the reaction rate at the lower stirring rates (Nomura et al 1972), is low due to magnetic nanoparticles in the aqueous phase. With increasing stirring rate, the latex size increased, since the particles coagulated and coalesced as a result of increase in the number of particle collisions (Nomura et al 1972). On the other hand, the reactions between magnetite surface and initiator also accelerated with further increase in stirring

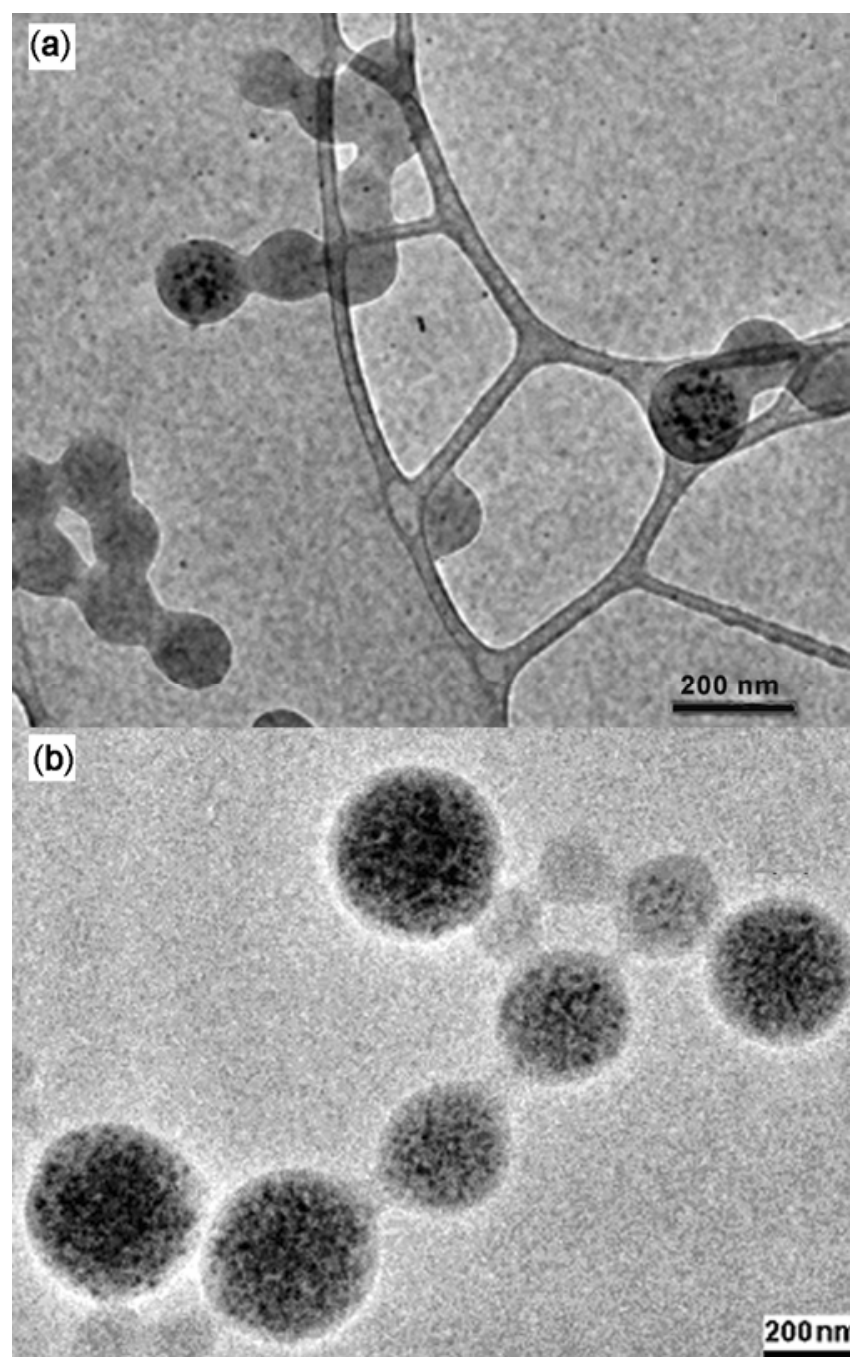

Figure 5. HRTEM photographs of magnetic latexes with adding rates of (a) $20 \mathrm{~mL} / \mathrm{min}$ (ML14) and (b) $4 \mathrm{~mL} / \mathrm{min}$ (ML11), at $500 \mathrm{rpm}$. 
rate and hence, smaller latexes were obtained. If the number of reactions between $\mathrm{Fe}^{+2}$ on the surface of magnetite and $\mathrm{S}_{2} \mathrm{O}_{8}^{-2}$ increases, it is expected that $M_{\mathrm{s}}$ values reduce too (Beyaz et al 2010). Indeed, $M_{\mathrm{s}}$ was decreased with increasing stirring rate as seen in table 1 . Another result confirming the statements was obtained from the analysis of polymer molecular weight by GPC. As the stirring rate was increased from 100 to $500 \mathrm{rpm}$, the molecular weight decreased from 102 to $69 \mathrm{~kg} \mathrm{~mol}^{-1}$ whereas the ratio of $M_{\mathrm{w}} / M_{\mathrm{n}}$ increased. In the previous studies (Beyaz et al 2010, 2011), it had been shown that the magnetite surfaces acted as a chain transfer agent and hence diminished molecular weight. Consequently, it was said that the interactions between magnetite nanoparticles and initiator fragments were more effective at high stirring rates.

\subsection{Adding rate for magnetic sol}

After primary experiments were carried out to find out how to add the magnetic sol to the polymerization system, the desired adding rates for stable latex without aggregates was determined and used in the parametric study (see table 1). The current parameter was studied for both 400 (series Va) and $500 \mathrm{rpm}$ (series V) of stirring rate. The characterization results exhibited that an increase in the adding rate of magnetic sol led to an increase in the magnetization and the molecular weight of latex, whereas the particle size decreased. The trend of increase at $M_{\mathrm{s}}$ and $M_{\mathrm{n}}$ is probably due to the decrease of surface area in which the interaction between magnetite nanoparticles and initiator fragments took place as simulated in figure 4. However, in order to understand the cause of the reduction in the particle size, electron microscopy images of ML11 (4 mL/min) and ML14 (20 mL/min) samples at $500 \mathrm{rpm}$ were taken and shown in figure 5 . At the high adding rate $(20 \mathrm{~mL} / \mathrm{min})$, small difference between the size of latexes without magnetite and the latex sizes with magnetite could be seen in the images. Also, it can be said that magnetite nanoparticles has shown better uniform distribution in the latex. For $400 \mathrm{rpm}$, when the adding rate was increased to $60 \mathrm{~mL} / \mathrm{min}$, there was no significant reduction in the latex size. Thus, it could be concluded that the adding rate is a more effective parameter at high stirring rates for latex size.

\section{Conclusions}

This paper presents the effect of new parameters on latex synthesis using a recently developed route. It was found that the reactions between naked magnetite surface and initiator fragments altered the known parametric properties of classic emulsifier-free emulsion polymerization. When KPS concentration and stirring rate were increased, the efficiency of reactions was increased that led to the formation of low magnetization and molecular weight. Also, the high monomer concentration caused an aggregation and the formation of unstable latex. With increasing amount of magnetic sol, the saturation magnetization and polymer molecular weight increased, whereas the bead size remained unchanged due to salt effect as a result of high electrolyte concentration. The higher stirring rate and the higher adding rate resulted in more uniform and smaller magnetic latexes and hence, their saturation magnetizations were found to be high. Thereafter, to obtain a more homogeneous distribution of magnetic nanoparticles inside polymer nanospheres and also more uniform magnetic latex, further work on the stirring rate, adding rate and magnetic amount might be performed since these nanoparticles are often preferred for in vivo biomedical applications like tissue repair or gene transfer.

\section{Acknowledgements}

This work was supported by Balikesir University Research grant no. BAP 2006/46. The authors would like to thank the State Planning Organization, Turkey, under grant no. $2005 \mathrm{~K} 120170$ for VSM system. The authors also thank the National Nanotechnology Research Centre (UNAM), Bilkent University for HRTEM analysis.

\section{References}

Babincová M, Šusteková E, Babinec P, Cicmanec P, Craciun V and Leszczynska D 2000 Czech. J. Phys. 50979

Beyaz S, Tanrisever T, Kockar H and Butun V $2011 \mathrm{~J}$. Appl. Polym. Sci. 1212264

Beyaz S, Tanrisever T and Kockar H 2010 Macro. Res. 181154

Beyaz S, Kockar H and Tanrisever T 2009 J. Opto. Adv. Mater. Symposia 1447

Block A P, Brown A R and Robinson D 2004 Proc. fourth int. conf. remed. chlor. recalcitrant comp. Montery, USA, p. 24

Can S and Tanrisever T 2007 J. Appl. Polym. Sci. 1032494

Dutz S, Clement J H, Eberbeck D, Gelbrich T, Hergt R, Muller R, Wotschadlo J and Zeisberger M 2009 J. Magn. Magn. Mater. 3211501

Faridi-Majidi R and Sharifi-Sanjani N 2007 J. Appl. Polym. Sci. 1051244

Faridi-Majidi R, Sharifi-Sanjani N and Agend F 2006. Thin Solid Films $\mathbf{5 1 5} 368$

Filipcsei G, Csetneki I, Szilagyi A and Zrinyi M 2007 Adv. Polym. Sci. 206137

Fitch R M 1973 Br. Polym. J. 5467

Gu S, Onishi J, Kobayashi Y, Nagao D and Konno M 2005 J. Col. Inter. Sci. 289419

Hasell T, Yang J, Wang W, Li J, Brown P D, Poliakoff M, Lester E and Howdle S M 2007 J. Mater. Chem. 174382

Horak D, Lednicky F, Petrovsky E and Kapicka A 2004 Macromol. Mater. Eng. 289341

Karaagac O, Kockar H, Beyaz S and Tanrisever 2010 IEEE Trans. Magn. 4612 
Kolthoff I M, Medalia A I and Raaen H P $1951 \mathrm{~J}$. Am. Chem. Soc. $\mathbf{7 3} 1733$

Lee C, Lin C, Chien C and Chiu W 2008 Eur. Polym. J. 442768

Liu Z L, Ding Z H, Yao K L, Tao J, Du G H, Lu Q H, Wang X, Gong F L and Chenc X 2003 J. Magn. Magn. Mater. 26598

Massart R 1981 IEEE Trans. Magn. 171247

Mornet S, Vasseur S, Grasset F, Veverka P, Goglio G, Demourgues A, Portier J, Pollert E and Duguet E 2006 Prog. Sol. Stat. Chem. 34237

Neuberger T, Schöpf B, Hofmann M, Hofmann M and Rechenberg B V 2005 J. Magn. Magn. Mater. 293483

Nomura M, Harada M, Eguchi W and Nagata S 1972 J. Appl. Polym. Sci. 16835

Philippova O, Barabanova A, Molchanov V and Khokhlov A 2011 Eur. Polym. J. 47542

Pich A, Bhattacharyaa S and Adler H J P 2005a Polymer 46 1077
Pich A, Bhattacharyaa S, Ghoshb A and Adler, H J P 2005b Polymer 464596

Sun S, Zeng H, Robinson D B, Raoux S, Rice P M, Wangand S X and Li G 2004 J. Am. Chem. Soc. 126273

Tanrisever T, Okay O and Sonmezoglu I 1996 J. Appl. Polym. Sci. 61485

Utkan G, Sayar F, Batat P, Ide S, Kriechbaum M and Piskin E 2011 J. Coll. Interf. Sci. 353372

Wang P, Chiu W, Lee C and Young T 2004 J. Poly. Sci. Part A: Polym. Chem. 425695

Wormuth K 2001 J. Col. Inter. Sci. 241366

Xie G, Zhang Q, Luo Z, Wu M and Li T 2003 J. Appl. Polym. Sci. 871733

Zaitsev V S, Filimonov D S, Presnyakov I A, Gambino R J and Chu B J. Col. Inter. Sci. 21249

Zheng W, Gao F and Gu H 2005 J. Magn. Magn. Mater. 288 403 